\title{
Der Traum ist das Aquarium der Nacht
}

\section{Erhard Taverna}

1 Aquarium - Tauchstation Wohnzimmer.

Gewerbemuseum Winterthur, bis 21. Oktober 2007.
Das Zitat von Victor Hugo aus «Les travailleurs de la mer» traf für mich auch umgekehrt zu, denn nachts träumte mir über Jahre von meinem Wasserbehälter auf dem nahen Schreibtisch. Die Fische trieben tot auf der Oberfläche, weil die Lüftung stoppte, die Pumpe ausfiel, der Filter versagte oder eine Kittfuge nachgab. Das auslaufende Wasser durchtränkte die Schulhefte und überschwemmte als endloser Wasserfall den Teppichboden. Aus allen Zimmerecken wucherten giftiggrüne Schlingpflanzen, und durch das Dickicht meiner Träume blitzten regenbogenfarbige Neonfische. Dann war es 1960 in allen Zeitungen zu lesen: Jacques Piccard war mit seiner «Trieste» in den Marianengraben abgetaucht. 10914 Meter unter Meer, was sollte da meine Miniaturwelt mit ihren Segelflossern und lebendgebärenden Guppys? Ich hatte es satt, die Algenpest zu bekämpfen und im Lavabo Tubifex zu züchten. Irgendwann danach verschwand mein erstes und letztes Aquarium aus meinem Leben. Melville und Jules Verne oder die einsetzende Pubertät, sie versprachen grössere Abenteuer, und meine arbeitsintensive Traumkiste verlor ihren Reiz. Jetzt lockten die
Tiefsee und Expeditionen am Meeresgrund. Echte Männer waren gefragt, Ozeanforscher oder zumindest Unterwasserarchäologen.

Aquarien und Abenteuergeschichten blieben unentwirrbar miteinander verwoben, die Tauchstation im Wohnzimmer und die donnernde Brandung vieler Küsten, die hypnotische Miniaturwelt und das Abenteuer einer Weltreise. Wer wieder eintauchen möchte in diese farbigen Gegenwelten und nachtdunklen Abgründe oder einfach noch einmal seinen Jugendträumen nachspüren will, hat dazu in Winterthur eine gute Gelegenheit. Bis zum 21. Oktober 2007 ist im Gewerbemuseum eine Ausstellung zum Thema Aquarium zu besichtigen [1]. Sie ist ästhetisch raffiniert gestaltet und bietet eine überraschende Kulturgeschichte von Madame Pompadours «Dorade de la Chine» bis zum beruhigenden Fischbehälter im Wartezimmer einer Arztpraxis oder dem schwimmenden Vorrat im Feinschmeckerlokal. Das Aquarium kommt in allen Aspekten vor, als Zierde im Wohnzimmer, als Publikumsmagnet grosser Anlagen oder gläsernes Labor der Naturwissenschaft. Abwechslungsreich und witzig erfährt der Be-

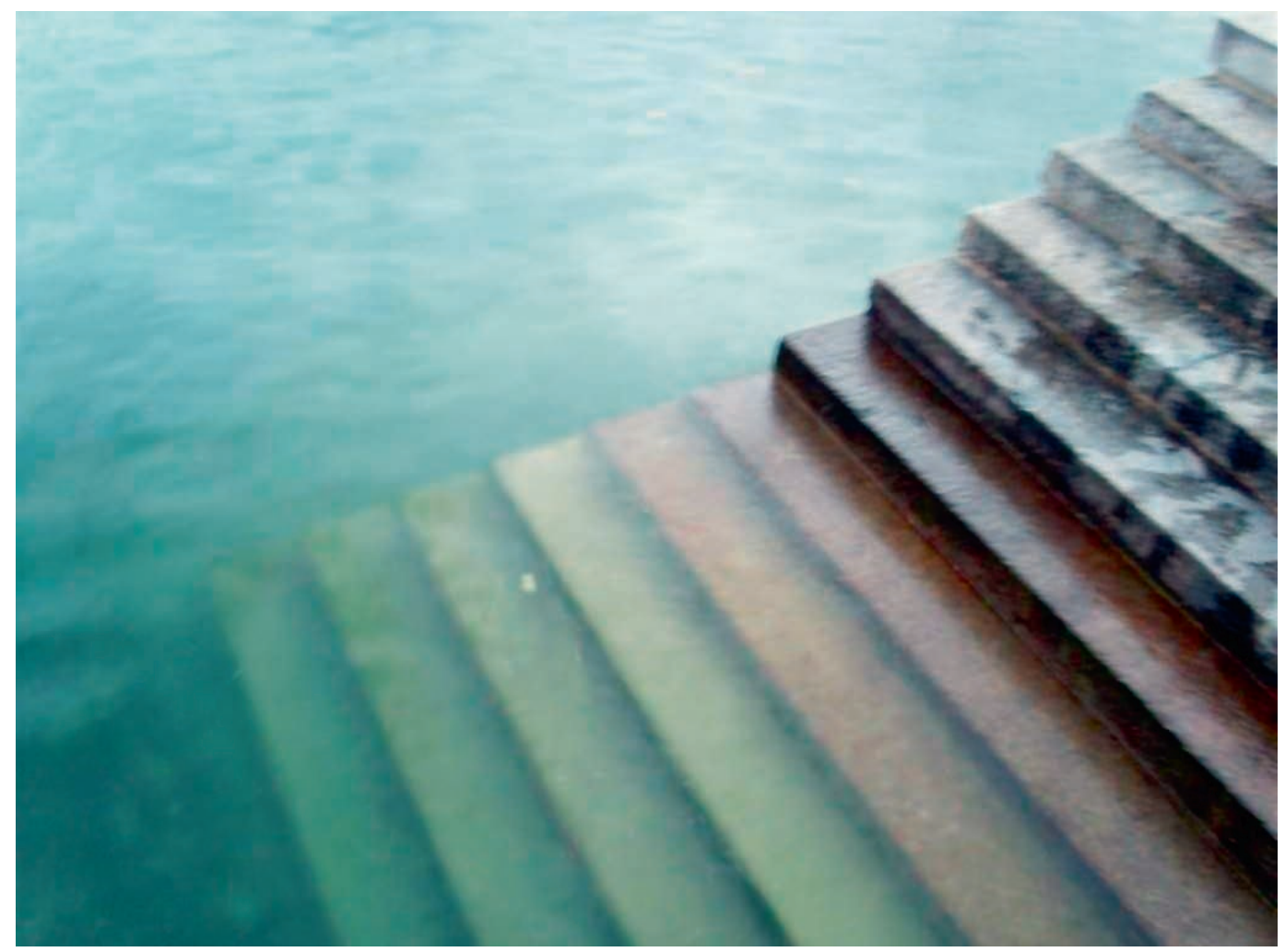

Bild: Micha Wagner 
2 Brunner B. Wie das Meer nach Hause kam. Berlin: Transit Buchverlag; 2003. 141 Seiten. trachter, wie die Europäer nach den Papageien und Kanarienvögeln die Muscheln und den Seetang nach Hause brachten, wie sich das Meer allmählich der modernen Neugierde erschloss, wie der biblische Leviathan zum Seepferdchen viktorianischer Salons mutierte. Wie so oft standen imperiale Entdeckungsfahrten und merkwürdige Freizeitgewohnheiten gebildeter Gentlemen am Anfang von Ursache und Wirkung. Der englische Chirurg Nathaniel Bagshaw Ward (1791-1868) erfand einen geschlossenen Glasbehälter für Pflanzen, ein Gewächshaus en miniature, das auch den weniger betuchten Patienten das Anlegen eines heimischen Tropendschungels ermöglichte. Der Wardsche Kasten förderte den Pflanzenanbau im britischen Imperium und gilt als Vorläufer des heutigen Aquariums. Doch das rechteckige Glasgefäss mit Leisten aus Birkenholz und Dichtungen aus Kitt hat erst der Engländer Philip Henry Gosse, inklusive Bezeichnung, dem Bürgertum schmackhaft gemacht. Die Presse lobte seine Verdienste begeistert: «[...] in all die geschmückten Paläste getaucht zu sein, die der alte Neptun so lange zögerlich unter Verschluss gehalten habe.» Ein an der Ausstellung erhältliches, sehr schön illustriertes Büchlein mit dem Titel «Wie das Meer nach Hause kam» ist auch dem Nichtbesucher zu empfehlen, weil es die Geschichte einer Erfindung nacherzählt, deren Siegeszug den Horizont von Generationen erweitert hat [2].

Dem schwäbischen Verfechter der Strumpfhose für den Mann und Begründer einer positiven Kleiderreform, Dr. med. et chir. Gustav Jäger, Professor für Physiologie, Anthropologie und Zoologie, verdanken wir einen Augenschein von 1860 in Wien aus dem ersten öffentlichen Meeresaquarium: «In einem Aquarium geht der Neuling suchend und sinnend umher, man sieht's ihm an, dass es in seinem Innern kocht und arbeitet; vor lauter Suchen bringt er es zu keinen behaglichen Genüssen, ja, man verzeihe mir den Ausdruck, er sieht so dumm drein, wie jemand in einer Gesellschaft, wo eine ihm fremde Sprache gesprochen wird.» 